\title{
Correction to: Effect of Boron on the Microstructure Evolution and Dynamic Recrystallization Kinetics of ALLVAC718Plus Superalloy
}

Hamideh Ershadikia, Gholamreza Ebrahimi, Hamidreza Ezatpour, and Amir Momeni

\section{Correction to: \\ JMEPEG \\ https://doi.org/10.1007/s11665-020-05258-y}

In the originally published article, the names of the first and third authors were misspelled. The correct spellings are Hamideh Ershadikia and Hamidreza Ezatpour, respectively.
The institutional affiliation for Dr. Ershadikia was also incorrect. The correct affiliation is Department of Materials and Polymer Engineering, Hakim Sabzevari University, Sabzevar, Iran. The authors regret the errors.

Publisher's Note Springer Nature remains neutral with regard to jurisdictional claims in published maps and institutional affiliations.

The original article can be found online at https://doi.org/10.1007/ s11665-020-05258-y.

Hamideh Ershadikia, Department of Materials and Polymer Engineering, Hakim Sabzevari University, Sabzevar, Iran; Gholamreza Ebrahimi, Department of Materials Science and Metallurgical Engineering, Engineering Faculty, Ferdowsi University of Mashhad, Mashhad, Iran; Hamidreza Ezatpour, Faculty of Engineering, Sabzevar University of New Technology, Sabzevar, Iran; and Amir Momeni, Department of Materials Science and Engineering, Hamedan University of Technology, Hamedan, Iran. Contact e-mail: r.ebrahimi@um.ac.ir. 